\title{
A propósito del Quijote
}

\author{
Manuel Herranz Martín \\ CEI, Instituto Complutense de Estudios Internacionales \\ IE University \\ mherranzm@faculty.ie.edu
}

DOI: http://dx.doi.org/10.15366/bp2018.18.017

Bajo Palabra. II Época. No18. Pgs: 337-354

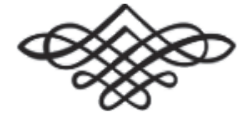


Recibido: 17/08/2017

Aprobado: 29/07/2018

\section{Resumen}

El texto es una revisión del significado del Quijote para señalar que su propósito realista, al tiempo que ejemplar, ha resultado tergiversado como consecuencia de la apropiación de la obra por parte del estado, pues la propuesta cervantina es humana y, por tanto, socava su carácter absoluto. Si bien, El Quijote también encierra una solución que no ha sido percibida en su propuesta de desarme o unión humana como sustitución de la división en estados o unidades armadas.

Palabras clave: Cervantes, Quijote, humanidad, desarme.

\section{Abstract}

This paper is a review of the meaning of the Quixote pointing out that its realist purpose, as well as exemplar, has been distorted once the state has taken possession of Cervantes work because its original concern is humanity and it, therefore, undermines the state's absolutist character. However, The Quixote also entails a way out which has not been perceived in its proposal for disarmament o human unity as replacement for our division in states or armed units.

Keywords: Quixote, Cervantes, humanity, disarmament. 
$\mathrm{E}$ I modelo literario de Cervantes en El Quijote se nos deja entrever en los dos únicos poemas de los que lo prologan que no refieren a los libros de caballerías y quedan además ambos bajo el mismo título: «Del donoso, poeta entreverado a Sancho Panza y Rocinante», siendo el poeta, lógicamente, el propio Cervantes. El poema dirigido a Sancho remite a La Celestina (1499) y el dedicado a Rocinante al Lazarillo (1554). Cervantes califica la obra de Fernando de Rojas como «libro, en mi opinión, divino si encubriera más lo humano», esto es decir, si no mostrase tan crudamente las bajezas humanas.

La Celestina no solo prolonga y exacerba el estilo realista que caracteriza a la literatura espańola de las tres culturas frente a la europea -algo que ha sido puesto de manifiesto por nuestros filólogos, entre otros por Menéndez Pidal al caracterizar al Mio Cid por su realismo como su distintivo frente a los otros cantares de gesta europeos, pero La Celestina además dirige una voluntariosa y aguda crítica contra el Idealismo, que en su tiempo se imponía inexorablemente en España en su forma gótica-cristiana. Nos presenta una visión realista del amor -uno de los más altos conceptos de la jerarquía idealista- mediante la descripción de la insensatez del enamorado y de cómo este es manipulado por aquellos que conocen su motivación y la pueden poner al servicio de sus intereses. Sin embargo, esos intereses o motivos de los manipuladores son la codicia y la lujuria; esos aspectos 'humanos' a los que refiere Cervantes que impiden que La Celestina sea un libro divino.

De modo que si la referencia al Idealismo como instrumento de manipulación no es desacertada en La Celestina y tampoco lo será en la picaresca en general, no deja por ello de asumir una parte consustancial de aquel al atribuir explícita o implícitamente la causa del mal a la naturaleza humana sometida a la corrupción del mundo sensible o sublunar, según se expresa Platón, de modo que la carencia de respuestas o soluciones alternativas al desenmascaramiento o desilusión de La Celestina nos aboca a un callejón sin salida cuyo temprano desenlace será El Guzmán de Alfarache,(1599), mediante el que Mateo Alemán expone la maldad irremediable de este mundo ante el cual solo nos cabe poner la vista en Dios y esperar en la otra vida, etc.

Cervantes disiente de este planteamiento así como de su resultado y asume el reto de mantener el punto de vista realista, pero ejemplarmente, esto es, expone el mundo tal cual es al modo de la picaresca sin el falso velo del Idealismo y manteniendo el esfuerzo por despertar a las personas de la simpleza avivando su discreción, pero, además, se propone ser ejemplar -modelo y referencia humana. 
Cervantes, digámoslo sin demora, encuentra el origen del mal en las circunstancias en las que se desenvuelve el ser humano, entorno que moldea su supuesta 'naturalezá, y ese medio ambiente es uno en el que se da el arma, la violencia y la guerra, ("que es lo mesmo las armas que la guerra» Discurso de las Armas y las Letras), pero el mal no es propio de la humanidad o naturaleza humana misma, esta es básicamente libre o tiene la facultad o capacidad de serlo, de adaptarse, pero nos ocurre que nos vemos arrastrados al mal reactivamente, involuntaria e incluso inconscientemente coaccionados por un contexto o condición cuyo elemento determinante es el arma.

La aparente falta de conexión entre las aventuras de don Quijote y la novela del Curioso Impertinente se nos desvela plenamente por su relación con ese propósito ejemplar cervantino que lo distingue y distancia de la picaresca al iluminar a ambos a una luz. La ejemplaridad que se propone Cervantes, tanto en El Quijote (1604) como en las novelas que llevan ese nombre, se nos manifiesta con la máxima intensidad en este extraordinario caso de los adúlteros virtuosos, ¿podría darse algo más alejado de los planteamientos de la picaresca? Y, sin embargo, comparte su esencia con el género en el objeto de mostrar - ¿qué mejor que con un caso de adulterio?- la distancia entre las figuraciones de las palabras, así como otras representaciones -particularmente la que hace Camila ante su marido- y los hechos reales que encubren, disimulan y distorsionan.

En el extraño caso del Curioso Impertinente Camila y Lotario engañan a Anselmo contra su 'voluntad' pues no es la lujuria o la falta de respeto de estos a su marido y a su amigo lo que les lleva al adulterio o a la traición sino las circunstancias, el condicionamiento al que les somete el loco Anselmo. Es el contexto, entorno o circunstancia la causa de su asocial conducta y no la maldad de la naturaleza humana. Se nos muestra además en la novela de modo minucioso cómo se produce también el cambio de determinación, mentalidad, principios o ideas de los fieles amigo y esposa hacia la condición de amantes adúlteros y traidores sometidos a la atracción de sus cuerpos. Cervantes lo expresa de este modo:

Rindióse Camila, Camila se rindió... Pero ¿qué mucho, si la amistad de Lotario no quedó en pie? Ejemplo claro que nos muestra que solo se vence la pasión amorosa con huilla y que nadie se ha de poner a brazos con tan poderoso enemigo, porque es menester fuerzas divinas para vencer las suyas humanas (Q. I. Cap XXXIIII. Donde se prosigue la novela de "El Curioso Impertinente").

Y hablando de fuerzas divinas, nótese el lugar de Dios - palabra suprema del Idealismo- en el Curioso Impertinente:

Pero, fiada en su bondad, se fio en Dios y en su buen pensamiento, con que pensaba resistir callando a todo aquello que Lotario decirle quisiese, sin dar más cuenta a su marido, 
por no ponerle en alguna pendencia y trabajo; y aun andaba buscando manera como disculpar a Lotario con Anselmo, cuando le preguntase la ocasión que le había movido a escribirle aquel papel. Con estos pensamientos, más honrados que acertados ni provechosos, estuvo otro día escuchando a Lotario, el cual cargó la mano de manera que comenzó a titubear la firmeza de Camila, y su honestidad tuvo harto que hacer en acudir a los ojos, para que no diesen muestra de alguna amorosa compasión que las lágrimas y las razones de Lotario en su pecho habían despertado. Todo esto notaba Lotario, y todo le encendía. (Q. I. Cap XXXIIII. Donde se prosigue la novela de "El Curioso Impertinente").

En la Segunda Parte del Quijote se mantiene este mismo propósito tanto desvelador como, al tiempo, ejemplar, algo que podemos ver explícito en el escrito de aprobación del licenciado Márquez Torres, atribuida sin controversia a Cervantes, en el que se incide muy repetidamente en ese carácter distintivo del Quijote en contraste con otros que quieren enseñar dando mal ejemplo:

Ha habido muchos que, por no haber sabido templar ni mezclar a propósito lo útil con lo dulce, han dado con todo su molesto trabajo en tierra, pues, no pudiendo imitar a Diógenes en lo filósofo y docto, atrevida, por no decir licenciosa y desalumbradamente, le pretenden imitar en lo cínico, entregándose a maldicientes, inventando casos que no pasaron para hacer capaz al vicio que tocan de su áspera reprehensión, y por ventura descubren caminos para seguirle hasta entonces ignorados, con que vienen a quedar, si no reprehensores, a lo menos maestros dél. Hácense odiosos a los bien entendidos; con el pueblo pierden el crédito, si alguno tuvieron, para admitir sus escritos; y los vicios que arrojada e imprudentemente quisieren corregir, en muy peor estado que antes, que no todas las postemas a un mismo tiempo están dispuestas para admitir las recetas o cauterios, antes algunos mucho mejor reciben las blandas y suaves medicinas, con cuya aplicación el atentado y docto médico consigue el fin de resolverlas, término que muchas veces es mejor que no el que se alcanza con el rigor del hierro." (Q. II. Aprobación del Licenciado Márquez Torres, Q. II)

En el año 1933 Dámaso Alonso publica El hidalgo Camilote y el hidalgo don Quijote, Itrabajo que, quizás desapercibido por el estallido de la guerra civil, reeditará en 1958 y otra vez en 1968 entre varios ensayos de su libro Del Siglo de Oro a este siglo de siglas. Dámaso Alonso señala la influencia sobre El Quijote del estrafalario personaje Camilote que aparece con su feísima amada Maimonda entre otros personajes del Primaleón (Francisco Vázquez, 1512), libro de caballerías que gozó de gran popularidad a tenor de las muchas ediciones que se hicieron a lo largo del siglo XVI. Seńala Dámaso Alonso siete coincidencias entre Camilote y don Quijote que considera excesivas como para ser obra de la casualidad. Solo les diferencia que

\footnotetext{
${ }^{1}$ Alonso, Dámaso (1933): «El hidalgo Camilote y el hidalgo don Quijote», Revista de Filología Española, no 20, págs. 391-397. Y ALONSO, Dámaso (1958): Del siglo de oro a este siglo de siglas. Madrid, Editorial Gredos (segunda edición en 1968).
} 
Camilote exige a caballero tras caballero confesar la belleza de la fea Maimonda o batirse con él en duelo a muerte y tras matar a varios caballeros resulta muerto él mismo a manos de don Duardos, mientras que don Quijote se nos presenta en un tono cómico. Pero señala Dámaso Alonso también que sobre don Duardos, el matador de Camilote, hace una versión el genial dramaturgo Gil Vicente, $L a$ Tragicomedia de don Duardos (Gil Vicente, 1522), en la que de modo idéntico a El Quijote se centra solo en el aspecto humorístico de Camilote y señala que Cervantes muy seguramente también leyó la obra de Gil Vicente dado el enorme interés por el teatro de Cervantes y nos consta su estancia en Portugal. Alonso concluye su ensayo en que, aunque El Quijote pudiera tener otras influencias, «ninguna de ellas explicaría la idea central del libro: la fe en la hermosura de su Dulcinea, su Maimonda, tratada en vano de ser impuesta al escéptico mundo». ${ }^{2}$

Diversos autores, como Maldonado de Guevara en La maiestas cesárea en el Quijote $^{3}$ de 1947 o José Antonio Maravall en El humanismo de las Armas en El Quijote 4 de 1948, han señalado que El Quijote es una crítica a los ideales imperiales españoles, particularmente a la cultura caballeresca y utópica importada con la corte de Carlos V, cuyo imperio, como el de su hijo Felipe II, se desplegaba hacia los cuatro puntos cardinales para hacer confesar: al Oeste conquistando América a fin de convertir a los indígenas al cristianismo, al Norte y Este luchando contra los anglicanos y protestantes y al Sur haciendo frente a los infieles turcos y musulmanes en general, al tiempo que reforzando también la confesión en el interior con la Inquisición como instrumento así como con las expulsiones de los judíos y los moriscos. Sostenemos aquí, sin embargo, que el significado del Quijote va más allá de cualquier coyuntura o momento histórico y entendemos como un importante malentendido de lo que sea el pensamiento realista, ciertamente del interés de muchos pensadores modernos espańoles, de Ortega y Gasset a José Luís Mora, transformar injustificadamente la circunstancia en historia ${ }^{5}$, pues en lo sustancial, en la realidad, la circunstancia humana es la misma en todo tiempo y lugar ${ }^{6}$.

\footnotetext{
2 Op. cit. p 396

3 Maldonado de Guevara, "La locura mayestática (La espiritualidad cesárea de la cultura española y El Quijote)", Revista de Estudios Políticos No 33-34, Instituto de Estudios Políticos (Actualmente Centro de Estudios Políticos y Constitucionales), 1947, Maldonado de Guevara volvería a publicar este escrito en el no 7 de Anales Cervantinos, 1958.

${ }^{4}$ Maravall, José Antonio, Humanismo de las Armas en Don Quijote, Instituto de Estudios Políticos, Madrid 1947.

5 Mora, José Luís, Bajo Palabra, "El Realismo español: palabras y cosas”, 2015, http://dx.doi.org/10.15366/ bp2015.10.023

${ }^{6}$ Otra cosa es que solo nuestro momento histórico de globalización hace realizable lo que no solo Cervantes sino otros importantes autores (Kant, Mozi, etc.) ya han entrevisto.
} 
La aventura de don Quijote que refleja nítidamente la actitud del hidalgo Camilote es la segunda, la del encuentro con los comerciantes toledanos, a los que don Quijote quiere hacer creer y confesar que Dulcinea es la más hermosa y así nos lo manifiestan las palabras claves del episodio que se repiten un buen número de veces en él, incluso una detrás de otra: " (....) habéis de creer, confesar, jurar, afirmar y defender...». (Q. I, Cap IV. De lo que le ocurrió a nuestro caballero cuando salió de la venta)

Ese modo de pensar realista lo utiliza de hecho la inteligencia, también conocida como servicio secreto de los estados, en tanto que pone entre paréntesis el contenido de la confesión o lo que piensen o esperen los creyentes de la misma; ir al cielo, ser felices, lograr justicia, etc. y atiende solo a su efectos reales en términos de alineamiento, sometimiento o toma de partido, con lo que podríamos decir que la novela de Cervantes publica, universaliza ese secreto, exponiendo la inteligencia por vez primera a los ojos del género humano, en feliz consonancia con el completo descubrimiento del mundo que se lleva a cabo en su época.

El idioma árabe, del que Cervantes tenía sin duda nociones, nos acerca también a esta perspectiva si consideramos que su palabra paz, salam, resulta ser lo mismo que sometido, fiel o creyente, muslim, todas estas palabras de la misma raíz slm que las aporta su significado. Ese punto de vista subyace en el Discurso de las Armas y las Letras, lectura difícilmente comprensible, si no quizás inadmisible para españoles o cristianos, cuando en él se lee que el Maestro enseñó a los suyos que "cuando entrasen en alguna casa dijesen: "Paz sea en esta casa".

Pese a la referencia de la segunda aventura al esclarecedor caso de Camilote, más intensa y detalladamente escenifica Cervantes en la primera esa inteligencia con la que sin escándalo nos quiere discretos (Q. I, Cap IV. De lo que le ocurrió a nuestro caballero cuando salió de la venta). El recientemente armado caballero encuentra a Andrés confesando y prometiendo, no podríamos decir que la verdad, pues claramente solo reacciona como mejor puede a los latigazos que le está propinando su amo. La llegada de don Quijote y su amenaza apuntando la lanza a la cara del labrador rico hace que sea ahora este el que entre en pánico y confiese y prometa. Incluso las sagradas matemáticas platónicas en las que se funda el idealismo filosófico son objeto de burla en virtud de la lanza amenazante; repasa: nueve meses a siete reales, setenta y tres reales, esa es la deuda con el pastorcillo establece don Quijote, a lo que no replica el atemorizado Juan. Finalmente, se retira don Quijote y Juan vuelve a flagelar a Andrés con redoblada sańa sin que el autor nos refiera o detalle los hechos que han generado el conflicto. No olvidemos que Cervantes es Dios, que necesariamente sabe todo, pues ese todo es justo lo que quiere saber ante el papel en blanco y, por lo tanto, solo es de interés para la historia el fenómeno de la fuerza actuando 
como motor de la confesión y sumisión, mientras que carece de él la llamada contradicción o causa puntual del conflicto, de la que el autor no nos da noticia, muy en contraste con lo puntual que es en aclararnos todo en el resto de las aventuras del caballero. Es también una aventura de especial brillantez y pertinencia en la crítica al modo de pensar idealista en tanto que suele tender a expresar que las armas solo actúan puntualmente y luego rige el 'derecho', sin embargo, el caso de Juan Haldudo nos manifiesta que la presencia de la amenaza de las armas es requerida para que se confiese y cumpla aquello acordado y prometido al acabar el tiempo que dura el desafío, guerra, destrucción mutua o violencia explícita.

Expuesto el inequívoco origen y destino del Quijote -el cervantino hay hoy que señalar- nos surge de inmediato una reflexión consecuente: ¿̇tampoco sus contemporáneos, o los más significados de estos, tenían duda de cuál era el sentido de $E l$ Quijote? Sabemos ya el temprano dictamen o, más bien, amenaza de Lope: «no hay poeta tan necio que alabe El Quijote» (Lope, 1604) ${ }^{7}$ pero, a despecho de Lope, $E l$ Quijote triunfó ante el «desocupado lector» al que apela Cervantes en el Prólogo; el lector sin función pública o militancia, frecuentemente remunerada, las Letras, y de ahí posiblemente la respuesta y el intento disolvente de la beata publicación de Avellaneda (1614) que coge a don Quijote de su mano para acabar dejándolo en el manicomio bajo la protección del Nuncio de Toledo.

¿Avellaneda? Bien pudo ser seudónimo de Lope, el Ave Fénix, a quien Góngora (1561-1627) en ocasiones llama "Llana" (Poema "Patos del aguachirle castellana»), en lugar de Vega, para poner de relieve su superficialidad. Igualmente, la repetida mención del «sinónimo voluntario» en el Prólogo al Quijote apócrifo bien puede referir a Camilote. Afortunadamente, Cervantes aún nos dejó otro Quijote cortado de la misma tela del primero para que no hubiese duda.

Y una buena muestra de ello la tenemos en el capítulo LVIII de la Segunda Parte, el que precede a la noticia del apócrifo, donde tiene lugar el famoso encuentro con los caballeros santos, pasaje que algunos exaltados autores leen como hito en ese peregrinaje del héroe hacia su destino en devotísima conversión. Las imágenes de estos caballeros están cubiertas y el texto abunda en descubrirlas, pues es muy propio del estilo cervantino repetirse en lo que quiere enfatizar:

Fue a quitar la cubierta de la primera imagen, que mostró ser la de San Jorge puesto a caballo, con una serpiente enroscada a los pies y la lanza atravesada por la boca, con la fiereza que suele pintarse.

- Este caballero fue uno de los mejores andantes que tuvo la milicia divina: llamóse don San Jorge y fue además defendedor de doncellas. Veamos esta otra.

7 Lope de vega, Félix Arturo (1604), Carta al Duque de Sessa 
Descubrióla el hombre, y pareció ser la de San Martín puesto a caballo, que partía la capa con el pobre; y apenas la hubo visto don Quijote, cuando dijo:

-Este caballero también fue de los aventureros cristianos...,

Pidió que quitasen otro lienzo, debajo del cual se descubrió la imagen del Patrón de las Espańas a caballo, la espada ensangrentada, atropellando moros y pisando cabezas; y en viéndola, dijo don Quijote:

-Este sí que es caballero, y de las escuadras de Cristo: este se llama don San Diego Matamoros, uno de los más valientes santos y caballeros que tuvo el mundo y tiene agora el cielo.

Luego descubrieron otro lienzo y pareció que encubría la caída de San Pablo del caballo abajo, caballero andante por la vida y santo a pie quedo por la muerte.

- Por buen agüero he tenido, hermanos, haber visto lo que he visto, porque estos santos y caballeros profesaron lo que yo profeso, que es el ejercicio de las armas, sino que la diferencia que hay entre mí y ellos es que ellos fueron santos y pelearon a lo divino y yo soy pecador y peleo a lo humano. Ellos conquistaron el cielo a fuerza de brazos, porque el cielo padece fuerza $^{8}$ (Q. II - LVIII Que trata de cómo menudearon sobre don Quijote aventuras tantas, que no se daban vagar unas a otras)

Y aún conviene continuar leyendo el capítulo para ver cómo don Quijote es, tal como dice, tan caballero como ellos. Después de explicar a Sancho lo que significa ¡Santiago y cierra España!, encuentran a un grupo de gente que se entretiene representando La Arcadia, gente que invita y trata muy cortésmente a don Quijote, quien, por ello, les quiere pagar con su moneda o virtud caballeresca y se pone en mitad del camino para hacer confesar como los caballeros santos, diciendo:

...sustentaré...que estas señoras zagalas... son las más hermosas doncellas y más corteses que hay en el mundo, excetando solo a la sin par Dulcinea del Toboso, con paz sea dicho de cuantos y cuantas me escuchan.

\section{Es entonces cuando llegan los lanceros con los toros}

Confesad, malandrines, así, a carga cerrada, que es verdad lo que yo aquí he publicado; si no, conmigo sois en batalla. (Q. II - LVIII Que trata de cómo menudearon sobre don Quijote aventuras tantas, que no se daban vagar unas a otras)

\footnotetext{
${ }_{8}$ Esta misma expresión, en la que equipara las ideas al cielo, se utiliza en el Discurso de las Armas y las Letras de la Primera Parte y expone el sentido del Quijote al que nos referimos, la percepción de Cervantes de las ideologías como confesiones forzadas a causa en último término del inmanente estado de guerra, u su consecuente necesidad de acatamiento en todo así en las consignas o maneras de significarse, pero ajenas al discurrir del pensamiento natural de las personas. Seguir luchando por valores e ideas es hacerlo contra molinos de viento, un ejercicio estúpido e inútil, se trata de que encaremos esa realidad, cuyo elemento determinante, como ya dicho, es el arma y la consecuente división humana en unidades armadas o estados, como se ve en que, en efecto, unirnos no es otra cosa que desmantelar fronteras y desarmarnos.
} 
Los hechos históricos del tiempo de Cervantes, tales como la expulsión de los moriscos así como las verdaderas historias de moros y renegados sirven para apuntalar la tesis novelística-histórica del Quijote. Y ahí tenemos como bien significativo ejemplo el diálogo con Lela Zoraida en el mismo capítulo y como introducción al discurso de las Armas y las Letras. A Zoraida le preguntan cuatro veces, cuatro, si estaba bautizada. Se adelantará a contestar en su lugar el cautivo y ella, aunque no está bautizada, «llena de angustia y donaire» interviene para decir que su nombre es María, Zoraida macangue -que quiere decir no, nos traduce el autor. ¿Pensamos, acaso, que les preocupaba a sus inquisidores la salvación de su alma? Si Zoraida se bautiza sus hijos serán buenos, matarán al lado de Santiago Apóstol, pero si Zoraida no se bautiza serán malos, demonios, endriagos, gigantes, yihadistas...... hasta hoy día.... ¿por los siglos de los siglos? Si entendemos nuestra circunstancia como historia -la evolución de las unidades armadas- entonces no busquemos solución, pues la hemos descartado de antemano. A esto, por cierto, refiere la enigmática aventura de los molinos de viento tomados por gigantes, historia bajo la cual Cervantes no pone nombre como hacia Orbaneja bajo sus pinturas.

La experiencia internacional de Cervantes como militar y, sobre todo, como cautivo cinco años en Argel motivó y aportó un elemento determinante a ese caldo de cultivo de la literatura realista española, tanto más ante la clara evidencia de la condición e igualdad humana básica, independientemente del ámbito, estado, religión o ideología en que se desenvuelva, en contraste con la incompatibilidad de sus figuraciones que, sin embargo, paradójicamente se presentan como nuestro medio propio de integración. No hay una figuración más realista que otra; el Idealismo nos hace vivir en un sueño, más bien una pesadilla, en una utopía trágica que nos impide comprender y encarar la realidad de la existencia humana que solo es captada por el discreto, el término que usa Cervantes.

La doctrina a la que hace referencia el Discurso de las Armas y las Letras es el $s i$ vis pacis parabellum, si quieres la paz, prepara la guerra -esto es, ármate, siempre más y más y más, y la historia pasada o futura no es otra cosa, de lo que nos resulta algo incuestionable, obvio y siempre presente y que también se nos oculta: que las armas, el negocio del estado, son la producción suprema del hombre y el extremo de toda su capacidad en todo tiempo y lugar. El sentido último del Discurso se obtiene en la horrible comprensión de que no hay diferencia alguna entre la circunstancia, las penurias de un soldado cristiano o español y de otro país o de otra religión o ideología cuyo destino es:

"y con todo esto, con intrépido corazón, llevado de la honra que le incita, se pone a ser blanco de tanta arcabucería y procura pasar por tan estrecho paso al bajel contrario. Y lo que 
más es de admirar: que apenas uno ha caído donde no se podrá levantar hasta la fin del mundo, cuando otro ocupa su mesmo lugar; y si este también cae en el mar, que como a enemigo le aguarda, otro y otro le sucede, sin dar tiempo al tiempo de sus muertes." (Q. I-XXXVII. Discurso de las Armas y las Letras)

El Quijote se propone desvelarnos la realidad humana oculta por el Idealismo, cuyo origen es la parcialidad o inhumanidad del estado o unidad armada, que controla tanto la muerte o los muertos como lo que se publica. Releamos la locura del hidalgo:

Se daba a leer libros de caballerías con tanta afición y gusto.... y más cuando llegaba a leer aquellos requiebros y cartas de desafíos.....y desvelábase por entenderlas y desentrańarles el sentido, que no se lo sacara ni las entendiera el mesmo Aristóteles, si resucitara para solo ello....se enfrascó tanto en su letura.....,y asentósele de tal modo en la imaginación que era verdad toda aquella máquina de aquellas soñadas invenciones que leía.....rematado ya su juicio....le pareció convenible y necesario hacerse caballero andante y irse por todo el mundo con sus armas y caballo.... Y lo primero que hizo fue limpiar unas armas... (Q I-I)

Si obviamos las poéticas especulaciones del caballero sobre los nombres, la actividad de don Quijote es proveerse de armas y armarse caballero, y esto último se consigue con simplemente velarlas, por cuanto exponer que le pertenecen es lo mismo que declarar soberanía, calidad de caballero o derecho propio y no subordinado al uso del arma, lo que adecuadamente le vale para dar comienzo a sus aventuras.

Lo usual es considerar las armas por su acción, esto es; la destrucción o muerte que puntualmente causan, sin embargo, el arma nos fuerza o determina virtualmente con la amenaza de daño y con la realidad de la privación, pero, lo que es más importante, sin que medie voluntad (malvada) alguna. Cervantes es bien consciente de ello y nos lo quiere mostrar de inmediato, por eso, las primeras personas que vieron a don Quijote en el mundo, las mozas de la venta

(....) como vieron venir un hombre de aquella suerte armado, y con lanza y adarga, llenas de miedo se iban a entrar en la venta" (y este) "coligiendo por su huida su miedo" (tuvo que retenerlas con palabras tranquilizadoras) “...no fuyan las vuestras mercedes...” (Q. I-II)

Y continúa con sus caballerosas palabras hasta mover a risa a las jóvenes. Entonces sale el ventero:

(....) el cual viendo aquella figura contrahecha, armada de armas tan desiguales, como eran la brida, lanza, adarga y coselete no estuvo en nada en acompañar a las doncellas en las 
muestras de su contento. Más, en efecto, temiendo la máquina de tantos pertrechos, determinó de hablarle comedidamente (Q. I-II)

La simple presencia de las armas sin que medie acción ni indicio de voluntad alguna es suficiente para provocar, en el primer caso, y modificar, en el segundo, el comportamiento de los presentes. Y más allá incluso de la presencia, el hecho de su simple existencia en la naturaleza, anterior a cualquier tipo de conciencia en el ser humano, es suficiente para constituirse en el elemento más determinante y nos lleva ineludiblemente a estar organizados en unidades armadas o estados y a que nuestra única forma de relación sea sumisión en un sistema jerárquico o cadena de mando o, de lo contrario, desafío, circunstancia a la que solo da respuesta la unión humana, que es lo mismo que el desarme.

Cuando vuelven a encontrarse en la venta con el barbero al que robaron el $b a-$ ciyelmo, la argumentación de don Quijote es la siguiente: sobre la albarda no sabe, pero sobre el yelmo que, por cierto, posiblemente le libró de la muerte a pedradas de los galeotes, dice

(....) fue, es y será yelmo de Mambrino, el cual se le quité yo en buena guerra, y me hice señor dél con ligítima y lícita posesión! (I-XLV Donde se acaba de averiguar la duda del yelmo de Mambrino y de la albarda con otras aventuras sucedidas, con toda verdad)

¿Medió, acaso, conflicto alguno para que pueda hablarse o no de legitimidad o licitud? Ninguno. Simplemente el yelmo -al menos para don Quijote- es un arma; pues, «que es lo mesmo decir armas que guerra». La argumentación sobre la ilegalidad de la acción de don Quijote se basa naturalmente en que el objeto en cuestión es civil, pero también una bacía, tal como la albarda, o una ínsula, son botín o ganancia de las armas, su privación, la justicia distributiva de la que particularmente se habla en la aventura de Roque Quinart, que es también motivo por el que Sancho acompaña a don Quijote. La propiedad privada no es primigenia, es una cesión eventual y condicionada de soberanía y la unión humana o desarme conduce, por tanto, al reino de los fines, a la comunidad humana.

En «Una visión cristiana de El Quijote», el título del prólogo de Julián Marías al libro de Denis Armand Gonthier, El drama psicológico del Quijote?, señala Marías que la idea del yelmo no es de don Quijote sino del barbero, al que se le ocurrió ponérselo en la cabeza. Pues bien, según esto se le ocurrió antes a Cervantes y así lo advierte y seńala con acierto Antonio Gómez Galán precisamente comentando esta

9 Armand Gonthier, Denys, El drama psicológico del Quijote. Prólogo de Julián Marías, Studium, Madrid, 1962 
misma escena en su artículo "El día y la noche en El Quijote»" "10 publicado en Arbor en 1961. Esta relación, que se percibe más allá o, mejor, antes de las palabras, nos muestra la intención escenificadora del autor del Quijote, y es también la que produce y capta la inteligencia, la facultad de los discretos y la carencia de los simples, pues tanto vale un si como un no -ambos son el movimiento de un poco de aire. Cervantes, dice Gómez Galán, hizo llover - CComenzó a llover un poco», se lee en el texto- para que el barbero se pusiera la bacía en la cabeza.

Marías expone brillantemente el concepto de la razón vital que comparte con Ortega en el primer capítulo de otro libro también relacionado con Cervantes y El Quijote, La imagen de la vida humana y dos ejemplos literarios: Cervantes y Valle Inclán ${ }^{11}$ donde afirma:

Lo que llamamos entender consiste en hacer que algo funcione dentro de mi vida. Se entiende, por ejemplo, lo que es un objeto, una pluma, un vaso, un cuchillo, anticipando en la imaginación la función vital que es escribir, o beber, o cortar, viendo el objeto en cuestión ejecutando virtualmente esa función; si yo muestro una pluma a alguien que no sepa qué es escribir, que no conozca esa posibilidad humana, jamás verá una pluma. ${ }^{12}$

El modo en que vivimos es, en efecto, anticipando (virtualmente). Sin embargo, Marías continúa:

Es mi proyecto el que se interpone y se intercala entre la realidad y yo, el que hace las cosas o cosifica lo real, porque el proyecto, que no solo es algo real sino una potencia realizadora, es él mismo una realidad imaginaria. Esto es una mesa porque proyecto sobre ella apoyar los codos, poner un libro o un vaso encima; pero se convierte en leña ante el proyecto de hacerla arder en la chimenea; en balsa como resto de un naufragio... ${ }^{13}$

Vemos aquí por qué Marías quiso hacernos notar que era el barbero quien proyectaba desde la bacía el yelmo, pero no es correcto decir que esto es una mesa porque yo proyecto apoyar los codos sobre ella sino más bien que ella me proyecta a mí esa posibilidad de apoyarlos o apoyar otras cosas. Por eso, el vitalismo ortegiano y español, que seguramente hunde sus raíces en la literatura del siglo XVI, resulta al fin un idealismo reseteado con la idea de 'proyecto'. No hay tal 'yo soy yo y mis circunstancias', en la realidad solo hay circunstancias. $Y$, en efecto, esta es la premisa con la que nos justificamos a nosotros mismos, mientras que no les reconocemos a los otros la misma condición.

\footnotetext{
10 Gómez Galán, Antonio (1961), «El día y la noche en el Quijote», Arbor No 49, p.185

11 Marías, Julián, La imagen de la vida humana; y dos ejemplos literarios: Cervantes y Valle Inclán, Editorial Revista de Occidente, Madrid, 1971

12 Op. Cit. p. 8

13 Op. Cit. p. 9
} 
Estamos de acuerdo con Marías en un buen trecho: si vemos una mesa patas arriba, afirmaremos sin duda alguna que está mal puesta, pero solo porque conocemos su uso, pues alguien que lo desconociera no podría decir si está mal o bien puesta -algo que ya afirmaba Marías al decir que quien no sabe para qué sirve una pluma no sabe que es una pluma aunque la tenga en la mano. Pero lo que aquí nos importa señalar es que no es necesario hacer consciente ese entendimiento del uso de la mesa sino que lo anticipamos incorporándonosla virtualmente, el pensamiento realista no existe sin el cuerpo. Con el arma sucede igual, solo que su incorporación virtual se nos genera de dos modos opuestos: empuñándola y encarándola y esa experiencia virtual, pero real, nos vuelve esquizofrénicos, nos divide e inoxerablemente nos enfrenta y su resultado es el conocido, si vis pacis parabellum, ármate todo lo que puedas aún contra la buena idea de que lo racional, humano y bueno sería la cooperación de todos por el beneficio común.

Vivimos, en efecto, anticipando, preocupándonos de cómo mejorar y, sobre todo, conservar la vida pero nos resulta que, en general, lo más urgente e importante es ocuparnos de lo que está ahí ya para directamente quitárnosla, y cuyo efecto real inmediato y constante es la privación.

Si el prólogo al Discurso de las Armas y las Letras es el de la inquisición a Zoraida, su epílogo es la historia del cautivo en el que nos presenta Cervantes la «bandera blanca de paz» en el momento crucial del encuentro y vínculo entre ambos miembros de los irreconciliables e incomunicables bandos.

La bandera blanca es la señal que ofrece una referencia alternativa e inequívoca ante las Armas y nos infunde el espíritu necesario para detener la violencia que permita y active la comunicación para la unión o el desarme, que 'es lo mesmo decir desarme que comunidad humana'.

Con el desarme o unidad humana las figuraciones idealistas desaparecerán como el humo cuando cesa el fuego, pues ese cambio de circunstancias también resultará en compartir el modo natural humano de pensar.

La historia del cautivo en Argel tiene en Cervantes dos antecedentes: una primera en Los baños de Argel, compendio de lugares comunes que ha dado lugar a considerar esta obra como diseñada para recaudar dinero para los cautivos a base de conmover o sugestionar al espectador y otra posterior, Los tratos de Argel, obra mucho más compleja y sutil que, representada, mostrará repetidamente el paño blanco al espectador desde las ventanas sobre el escenario, aunque no se mencione con el nombre bandera blanca que propiamente es un término militar, un término de las Armas.

Pero vayamos a la Segunda Parte, al capítulo XVII tan famoso de los Leones titulado «Donde se declaró el último punto y estremo adonde llegó y pudo llegar 
el inaudito ánimo de don Quijote con la felicemente acabada aventura de los leones».

Tal como hemos mencionado, la intención del autor realista se obtiene cuando se capta el artificio de la escenificación, esto es, el acopio por la fuerza impensada del azar -como lo fue la lluvia para el yelmo de Mambrino- de los componentes y factores necesarios para que se produzca el hecho deseado, en este caso la aventura de los requesones, que no es una simple broma o anécdota; con ellos se ducha a don Quijote de suero, de modo que se nos hace verosímil que no se lo meriende el león y le sirve igualmente al autor para que aparezca el paño blanco, el objeto necesario para dar fin a la aventura que ya se nos anunciaba en el capítulo previo como «la del carro de las banderas». Es la simple vista en la lejanía del «carro de las banderas» la que hace requerir apresuradamente a don Quijote las armas, seguro de que con las banderas se acerca la ocasión de la hazaña. Y ya en el capítulo XVII (releer el título), según se va acercando, se menciona otra vez el «carro de las banderas», en total cuatro veces, cuatro, todo para que, una vez que el león desprecie a don Quijote, éste pide al leonero que cierre la jaula:

Hízolo así el leonero, y don Quijote, poniendo en la punta de la lanza el lienzo con que se había limpiado el rostro de la lluvia de los requesones, comenzó a llamar a los que no dejaban de huir ni de volver la cabeza a cada paso, todos en tropa y antecogidos del hidalgo; pero alcanzando Sancho a ver la señal del blanco paño, dijo:

-Que me maten si mi señor no ha vencido a las fieras bestias, pues nos llama. (Q. II, Cap. XVII. Donde se declaró el último punto y estremo adonde llegó y pudo llegar el inaudito ánimo de don Quijote con la felicemente acabada aventura de los leones)

La bandera blanca no equivale a rendición sino al contrario, a la manifestación del entendimiento de nuestra interdependencia. Cesar unilateralmente en el uso de la violencia, del fuego, del emprendimiento para el daño (la producción de armas) e incluso en la inhumanidad requerida para competir resulta en lo contrario de lo que se pretende, en la sumisión, en el servicio y, prácticamente, en la integración en otra unidad armada (asaz del previo aumento de la violencia en la original para compensar la deserción del que no colabora para la destrucción) y, por último, incluso en la posibilidad misma de hablar, proponer. En efecto, el desarme unilateral no es tal, no es viable, el desarme solo puede llevarse a cabo con la cooperación de todos.

Pero, esto no es óbice para que la propuesta si requiera la unilateralidad -que es lo que realmente sucede con el levantamiento de la bandera blanca -el punto y estremo al que pudo llegar Cervantes, momento en el que todavía no se ha producido desarme alguno. 
La sustitución de nuestra actual división en unas 200 unidades armadas por la unión humana solo puede realizarse con el acuerdo y la coordinación de todos. Si nos unimos, es decir, si nos des-insulamos, si vivimos juntos o convivimos, ¿Cómo podría haber ejércitos? Ni siquiera uno, pues obviamente son unos por otros y no por otro motivo. Ni siquiera existirá el objeto arma, pues, igualmente, unidos, ¿cómo podríamos admitir el emprendimiento para el daño, lo que, sin embargo, ahora es la actividad humana suprema? Pero, ni siquiera se trata de eso, se trata de que el desarme mismo es la construcción de la comunidad humana. 


\section{ReferenCias Bibliográficas}

Alonso, DÁmaso, Del Siglo de Oro a este siglo de siglas, Madrid, Gredos, (segunda edición) 1969.

Castro, Américo, El pensamiento de Cervantes. Madrid, Editorial Hernando, 1925

- Cervantes y los casticismos españoles, Barcelona, Alfaguara, 1966.

Close, Anthony, The romantic approach to 'Don Quixote', Cambridge University Press. Cambridge, 1978.

Díaz Plaja, Guillermo, La técnica narrativa de Cervantes, Barcelona, Diputación Provincial de Barcelona, Biblioteca Central, 1949.

Gaos, Vicente, Cervantes, novelista, dramaturgo y poeta, Barcelona, Planeta, 1979.

Giménez Caballero, Ernesto, Don Quijote ante el mundo (y ante mi), Puerto Rico, Inter American University, 1979.

Maravall, José Antonio, Utopía y contra-utopía en El Quijote, Santiago de Compostela, Pico Sacro, 1976.

Marías, Julián, El Alción. Imagen de la vida humana, Madrid, Editorial Revista de Occidente, 1971.

Mora, José Luis, "Lecturas filosóficas del Quijote", Gran Enciclopedia Cervantina, v. V, Dir. Carlos Alvar, Madrid, Castalia, 2008.

Ortega y Gasset, José, Meditaciones del Quijote: Ideas sobre la novela, Espasa-Calpe, 1964

Rey Hazas, Antonio, Poética de la libertad y otras claves cervantinas. Madrid, Eneida, 2005

Rey Hazas, Antonio y Muñoz Sánchez, Juan Ramón, El nacimiento del cervantismo. Cervantes y El Quijote en el siglo XVIII, Madrid, Verbum, 2006.

Rosales, Luis, Cervantes y la libertad, Madrid, Ediciones Cultura Hispánica, 1985 Unamuno, Miguel de, Vida de don Quijote y Sancho. Obras Completas, Madrid. 1967

Zambrano, María, Cervantes (Ensayos de crítica literaria). Ed. Enrique Baena, Málaga, Ed. Málaga, Fundación Málaga, 2005

DOI: http://dx.doi.org/10.15366/bp2018.18.017

Bajo Palabra. II Época. No18. Pgs: 337-354 
